\title{
INFIDELIDADE PARTIDÁRIA E REPRESENTAÇÃO POLÍTICA: alguns argumentos sobre a migração partidária no Brasil ${ }^{1}$
}

\author{
Andíá Freitas*
}

\section{INTRODUÇÃO}

A relação entreas trocas de partido efetiva das por políticos e a representação política pode parecer, a princípio, óbvia. Vários analistas que investigaramo fenômeno da troca partidária ou da migração partidária, no Brasil, levantaram hipóteses explicativas sobreas conseqüências perversas que as trocas de legenda podem trazer para a representação.

O principal argumento desses autores éde queos parlamentares, ao trocarem de partido, acabam por promover um afastamento entrea vontade expressa do el eitor e sua representação, o que acarretaria uma crise de representatividade, ou, mais especificamente, uma viol ação do princípio segundo o qual o eleitor é quem determina a distribuição dos cargos el etivos. ( LimaJr., 1993, p.30; Marenco, 2006, p.1; Melo, 2004, p.152).

* Mestranda em Ciência Política pela USP. Pesquisadora permanente do Centro Brasileiro de Análise e Planejamento - CEBRAP.

Rua Morgado de Mateus, 615. Cep: 04015-902. São Paulo - Brasil. amfreitas1@gmail.com

${ }^{1}$ Agradeço os comentários preciosos de Umberto Freitas, Fernando Limongi e Adrian Gurza Lavalle.
Isso ocorreria porque o voto do eleitor, no sistema eleitoral brasileiro, é, ao mesmo tempo, partidário e pessoal, pois promovea distribuição das cadeiras entre os partidos e define a ordem dos eleitos. Ou seja, a soma dos votos dados a todos os candidatos do partido ou da coalizão de partidos e dos votos dados à legenda do partido ou dos parti dos quecompõem a coal izão determina o número de cadeiras a que cada partido ou coalizão tem direito, e os votos dados aos candidatos, individual mente, ordenamaqueles queocuparão as cadeiras definidas para os partidos ou paraa coalizão.

Com basenessa ambivalência implícita ao sistema eleitoral brasileiro, esses analistas argumentam quenão importa sea intenção do el eitor, ao votar, édar um voto pessoal, ou um voto partidário. O mandato pertenceria ao partido. Empiricamente, argumentam ainda que poucos candidatosultrapassamo coeficienteeleitoral com sua votação individual. Isso significa que quase todos os parlamentares eleitos dependeriam do mecanismo de transferência de votos no interior do partido ou da col igação para consegui rem sua 
cadeira, o quereforçaa tese deque o mandato pertenceao partido enão ao candi dato eleito.

O que esses autores indagam é se o meca nismo eleitoral concedeo mandato ao parlamentar ou ao partido. E sua resposta équeo voto do eleitor distribui as cadeiras entre os partidos. No entanto, esseargumento não éunânime, pois al egislação eleitoral não éexplícita quanto a esseponto. O sistema eleitoral brasileiro éum sistemadelista aberta, em que os el eitores enão os partidos definem quem ocupa as cadeiras, o que poria em dúvidaaquestão do pertencimento do mandato. Mas, se a tese desses autores está correta, o parlamentar, ao trocar de partido, promoveria um afastamento entre o voto do eleitor dado nas urnas e a distribuição de poder entre os partidos no parlamento e, nessecaso, a migração partidária resultaria em uma crisederepresentatividade.

Essaé, sem dúvida, uma questão relevante, mas a temática da representação políticaultrapassa o mecanismo detransformação devotos em cadeiras, pois importa, sobretudo, o tipo derelação queessemecanismo estabelece. Ou seja, ocupa-se maiscomarelação entre orepresentado eo representante.

Esse aspecto envolve outras implicações problemáticas, já que os partidos são instâncias intermediárias que se constituem em canal que vincula eleitor e eleitos, mas não se explicitam facilmentena teoria da representação, baseadana relação entrerepresentanteserepresentados. Apesar deo papel dos partidos políticos estar absolutamenteindissociável nessa relação, nas democracias representativas, tal papel apareceapenas nas entrelinhas do debateteórico sobre representação política. A questão subjacenteàanál ise, portanto, quevinculaatroca partidáriaà representação políticaé: a quem pertenceo mandato? Ao parlamentar ou ao partido? E essa é uma questão ainda em aberto, tanto na teoria da representação como na literatura quetrata de partidos políticos.

Os objetivos destetexto são, portanto, bastante modestos. Seu intuito é tão somente trazer al guns argumentos que permitam discutir as relações entre a migração parti dária e a repre- sentação política eul trapassem as interpretações restritas ao procedimento ou às regras deconversão de votos em cadeiras.

\section{MIGRAÇÃO PARTIDÁRIA NO BRASIL: a manifestação na conjuntura}

O fenômeno da migração partidáriano Bra sil ressurge ${ }^{2}$ mais explicitamentecom o processo detransição do regimeautoritário para a democra cia. E se divide claramente em dois momentos, sendo o primeiro desses diretamenter relacionado à própria transi ção democrática, ou seja, a um processo natural dere-acomodação das lideranças; já o segundo momento foi iniciado com o governo Fernando HenriqueCardoso. As motivações para as trocas, a partir desse período, ai nda carecem de explicação.

Duranteo regimeautoritário, não ocorreram trocas de legendas, pois a infidel idade partidária era passível de punição com perda do mandato e foi regulada pela Lei 4.740 de 1965, cujo artigo 72 explicita que os filiados a um partido, detentores de mandato el etivo, que se opusessem às diretrizes desse partido - trocando de legenda ou votando contra a indicação de seu líder - perderiam o mandato.

Em 1979, com o processo de liberal ização política, promulgou-seaLei 6.767 , quepermitiua criação denovos partidos ereinstituiu a possibilidadedeorganização parti dária, negada duranteo regimemilitar. Essemomento deabertura política caracterizou-se pela criação de novos partidos PMDB, PDS, PTB, PP, PDT e PT - que impulsionaram as primeiras trocas delegenda.

No período seguinte, de 1979 a 1995, as trocas delegenda estavamfortementevinculadasà instabilidade política, ou às mudanças inesperadasnalegislação eleitoral ou partidária, típicas de um período de transição. Em 1981, observou-se

\footnotetext{
2 O fenômeno ressurge com a transição, pois ocorrera no período democrático anterior, entre 1946 e 1964. Nessa época, o volume de trocas de legenda, embora inferior ao da democracia atual, estava longe de ser insignificante (Cf. Zulini, 2008).
} 
um movimento migratório ligado à nova lei eleitoral, instituída deformaad hoc. Em 1985, adisputa acirrada pela sucessão presidencial acabou por dividir o PDS (Partido Democrata Cristão), antigo ARENA (AliançaRenovadora Nacional), levandoà criação do PFL (Partido daFrenteLiberal). Surgem, ainda, mais oito novos partidos, dois deles comunistas, tirados dailegal idadesó em maio de 1985.

Após essafaseinicial, em 1988, período que encerra o processo de transição democrática, com a promul gação da nova Carta Constitucional, observa-se outro grande movimento migratório de reacomodação de parlamentares na Câmara dos Deputados, impulsionado pela disputa eleitoral de 1989. Novamentea criação denovos partidos - o PSDB (Partido da Social Democracia Brasileira) eo PRN (Partido da Reconstrução Nacional) - e as estratégias parti dárias para aumentar o tempo de utilização do horário eleitoral gratuito levaram a uma intensatroca delegenda no interior da Câmara dos Deputados (Diniz, 2000; Freitas, 2007).

No entanto o PRN, criado às vésperas da eleição presidencial, desaparece logo após o impeachment do presidente Fernando Collor, le vando seus filiados a procuram abrigo em outras agremiações. Atéentão, o sistema político brasileiro estava marcado pel o seu caráter de exceção e transição: assunção atípica de dois vice-presidentes (por falecimento e por impeachment); reordenamento jurídico dado pela nova Constituição; eleição direta do primei ro presi dente; ecatorzemodificações efetivadas nal legislação eleitoral e partidária, entre1979 ea Nova Constituição.

Assim, não seria demais supor que tamanha instabilidade influenciasse parlamentares a trocarem de partido. Outros países onde ocorre ram mudanças de regi meegrandes mudanças na legislação eleitoral e(ou) partidáriatambémforam acometidos por uma intensa movimentação entre as legendas; tal éo caso de Rússia, Hungria, Polônia eUcrânia, Espanha, Filipinas, Tai wan, Japão eltália (Desposato, 2006; Mershon; Heller, 2005).

Assim, só a partir da eleição de Fernando HenriqueCardoso para a Presidência da Repúblicaéquese podeconsiderar queo sistema político brasi leiro adquire certa estabilidadee seconsol ida. É nesse momento também que as trocas de legenda apontam para uma estabilização do fenômeno, concentrando-seem períodos específicos das legislaturas, principal mente, nos meses de fevereiro do primeiro e do terceiro ano da legisl aturae no período que antecede o fim do prazo mínimo de filiação com vistas à eleição seguinte, seja ela municipal ou federal (Freitas, 2008; Limongi; Freitas, 2005; Melo, 2004).

Araújo (2000) afirmaaindaqueésomentea partir da legislatura que se inicia em 1995 que o movimento demi gração parti dária se regulariza, invertendo o seu sentido, ou seja, ao invés de se dar em direção aos novos e pequenos partidos, ela passa a ocorrer na di reção dos grandes partidos.

A partir da el eição do presidenteFernando Henrique, as migrações partidáriasnão podem mais ser explicadas pela transição e pelo ajuste institucional. Os estudos que se dedicaram ao tema, no Brasil, ainda não el uci dam o porquêdas incessantes trocas delegenda. Suas principais hipóteses giram em torno da idéia de que os parlamentares querem aumentar suas chances desereeleger e, diante do imperativo da sobrevivência política, acabam por trocar delegenda, procurando partidos melhor posicionados junto ao governo (Melo, 2004).

No entanto, Freitas e Limongi (2005) de monstram queas trocas del egenda entrepartidos externos à coalizão governista para partidos da coal izão governista representam $13 \%$ do total das migrações durante o governo Fernando Henrique. No governo Lula, esse percentual sobe para $27 \%$ do total das migrações. Ainda assim, não épossível explicar as trocas delegenda apenas pela afirmação deque os parlamentares trocam departido no sentido da coalizão governista, procurando, assim, maximizar seu acesso a recursos públicos quesó o Executivo teria como disponibilizar.

Do ponto de vista do comportamento parlamentar, Freitas eLimongi demonstram queas migrações implicam poucas mudanças, pois os parlamentares trocam para partidos que votam de maneira muito semel hanteentresi, o quesignifica 
queastaxas deapoio dos parlamentares, tanto em relação ao governo como em rel ação ao líder de seu partido, antes edepois das trocas, teriam alteraçõesinsignificantes.

Ou seja, a teseda migração partidária voltadapara maximizar aschances desucesso eleitoral num movimento em direção à coal izão governista, demodo a converter o apoio ao governo em recursos, eos recursos em votos, nas el eições seguintes - não é suficiente. Para atestá-la seria necessário compreender os ganhos queo deputado migrantee o partido queo recebepodemobter quando háuma troca defiliação partidária. E não setemaindauma respostasuficientepara essa questão.

A migração partidária, portanto, é um daqueles temas árduos da ciência política no Brasil, em primeiro lugar, pela insuficiência de explica ções teóricas respal dadas em pesqui sas capazes de explicá-la. Em segundo, por força de uma visão influenciada por uma cultura política que considera esses fenômenos como "típicos" do comportamento político brasileiro, ou dequesó aqui elas ocorrem na quantidade em que ocorrem, ${ }^{3}$ o que acaba por deslocar a questão da expl icação analítica, simplificando-aeprivilegiando aspectos folclóricos da nossa política.

O ponto central dessas considerações éque ainda não se dispõe de um conjunto de estudos detal hados que expl icite a motivação dos parlamentares para atroca del egenda, dificultando entender as conseqüências do fenômeno para o sistema político e para a representatividade do mandato, questão que problematiza o processo demigração partidária.

Como foi explicitado, aliteratura quetrata do tema no Brasil afirma, deforma al igeirada, que a migração partidária teria conseqüências perversas para a representação. Para esses autores, as tro-

\footnotetext{
${ }^{3}$ Entrefevereiro de 1987 eabril de 2008 , cerca de $27 \%$ dos parlamentares brasileiros trocaram de partido pelo menos uma vez, ao longo de seu mandato. O volume impressiona, mas não constitui exclusividade do sistema político brasileiro. Na Itália, por exemplo, aproximadamente $25 \%$ dos parlamentares trocaram de legenda pelo menos uma vez, entre 1996 e 2001. Ao trazer esses números, não se quer banalizar o tema, mas apenas demonstrar que as trocas de legenda ocorreram e ocorrem em diversos países (Mershon; Heller, 2005).
}

cas de legenda promoveriam um afastamento entrea vontadedo el eitor ea distribuição decadeiras entre os partidos no parlamento, o que levaria a uma crise de representatividade (Lima Jr., 1993, p.30; Marenco, 2006, p.1; Melo, 2004, p.152). Essa resposta éapressada, primei ramente porquealegislação eleitoral deixa na mão do el eitor o ordenamento dos el eitose, sendo assim, criauma situação dúbia, em que não é possível definir a quem pertence o mandato, mesmo olhando apenas para o sistema eleitoral. O próprio Tribunal Superior Eleitoral, querecentementedecidiu que o mandato pertenceao partido enão ao candidato, quando foi consultado sobreamesma questão, em 1989, decidiu, por unanimidade, que não havia bases na legislação el eitoral eparti dária para definir que o mandato pertenceao partido. Sendo assim, aquestão épouco clarae, mesmo quesetome a questão da representação apenas pelas regras de conversão decadeiras em votos, não se pode afirmar queo mandato pertenceao partido.

\section{REPRESENTAÇÃO OU GOVERNABILIDADE: 0 debate institucionalista}

Outraabordagem sobrea mi gração parti dária consi dera como um dos componentes fundamentais da fidelidade partidária o grau de institucional ização dos sistemas partidários. Nessecaso, a fidelidade parti dáriaéentendidaa partir da ótica segundo a qual, em sistemas representativos, a ordenação das preferências é função dos partidos políticos, eo bomfuncionamento dossistemas políticos estaria diretamenterelacionado à capacidade de os líderes partidários induzirem os parlamentares à cooperação.

Ou seja, segundo essa visão, as instituições eleitorais e parlamentares produzem incentivos para o fortalecimento dos partidos políticos, dando-Ihes mei os para aplicar sanções aos membros indisciplinados, o quelhes possibilita serem capazes não apenas de coordenar as decisões, mas também deimpedir queos parlamentares, preocupados em aumentar suas chances de sucesso na 
carrei ra política, procurem apenas atender a seus eleitores deformaclientelista.

Essa perspectiva entendeque os interesses dos parlamentares são sempre particularistas e paroquiais, equeos partidos políticos, em umsistema institucionalizado, trariam à pauta questões nacionais. Assim, a análiseda migração partidária écol ocada ao lado da tese da disciplina partidária e da coesão interna dos partidos.

Esse debateinstitucional ista estámuito distante do debate teórico da representação política, pois, nessecaso, a questão principal éa capacidade deas instituições garantirem a governabilidadeou impedirema paral isiadecisória. O queimporta aqui équeas decisões sejamtomadas. Como as decisões são tomadas dentro dos partidos não étão importante, desde que eles sejam disciplinados. Obviamente, émel hor quesejam coesos, mas, comoveremos a seguir, a coesão partidária, por si só, não garantedecisões unânimes dentro dos partidos.

Essa matriz de análise, que acompanha o debate sobre mi gração partidária, leva autores a afirmarem que a mi gração afeta a representação política deforma negativa. No entanto, essa não é uma questão relevanteentreos teóricos quetratam da representação política. A noção de representatividade entendida pelos autores que tratam da migração partidária - e que se refere à diferença entrea vontadeexpressa pel os eleitores nas urnas ea distribuição decadeiras entreos partidos políticos- não éa mesma representatividade que aparecena teoria da representação, em quea questão serelaciona com a dual idadeconstitutiva própria da representação pol ítica no Brasi I, como apontado no início. A ambivalência da representação seexpressa namanutenção de um equilíbrio frágil entre a idéia de que o representante representa a nação, mas, ao mesmo tempo, não deve perder o fio condutor que o liga ao el eitor. Sendo assim, entender quais as conseqüências da migração partidária para a representatividade exigiria entender o papel mediador dos partidos políticos nessa relação. E isso não ésimples, como veremos aseguir.

\section{PARTIDOS POLÍTICOS: a questão da unida- de partidária e autonomia do representante}

A definição de partidos políticos de Burke é: party is a body of men united, for promotion by their joint endeavours the national interest, upon some particular principle in which they are all agreed" (Burke, 1981, [1770], p.317). Sartori (1983) acrescenta a essa definição que, entre os objetivos dos partidos, está a sel eção e a apresentação de candidatos nas eleições, com o intuito deinfluenciar as políticas governamentais.

Sartori substitui os princípios que Burke apresenta como uma unanimidade entre os membros por "princípi os gerais ou tendências com as quais concordaa maioria deseusmembros" (1983, p.81).

Downs (1999), por sua vez, informa que partidos políticos constituem uma coal izão deindivíduos quebuscam, através demeios legais, controlar o aparato governamental . O autor completa, definindo coal izão de indivíduos como o conjunto daqueles "quetêm certos fins em comum ecooperamentresi para atingi-los" (p.46). Downs afirma que essa descrição ampla, embora de acordo com a visão quetemos dos partidos políticos, traz problemas para a análise, pois a idéia decoalizão deindivíduos não pressupõequeeles concordem entresi.

Ou seja, os partidos políticos não são um bloco monolítico, o queleva Downsaconcluir que sua definição de partidos esbarra no dilema "da fal sa personal ização versus superindividual ismo" (p.46-47). O autor acrescenta, mais à frente:

... tomamos cada partido como se fosse uma pessoa; daí poder parecer ser uma falsa personificação. Admitimos que se trata de uma abstração do mundo real, já que, na real idade, nem mesmo os funcionários-chave dequal quer governo têm exatamente as mesmas metas (Downs, 1999, p.47).

Não podemos entender os partidos políticos como grupos de indivíduos que concordam entresi, não importa a questão em pauta. Obviamente, é desejável que esses indivíduos, ao se unirem, se articulem em torno de uma bandeira 
ou de princípios comuns pel os quais queiram lutar. Mas, quando eles, unidos por uma sigla partidária, chegam ao Executivo ou ao Legislativo, não basta que acreditem nos mesmos princípios gerais: el es têm de tomar decisões que nada têm a ver com as grandes ideologias, mas com decisões do cotidiano dos governos.

A questão a ser ressaltada é que a tomada de decisão no parlamento independe do quão institucionalizado seja o sistema partidário: mesmo que os partidos sejam os ideais, ideológica e social menteenraizados ecom membros coesos, a cada momento épreciso decidir sobrequal seráa posição do partido.

Aqui, temos umaquestão importantepara a representação política: apesar de sua dualidade constitutiva, emmomento al gumseentendequeos parlamentares representem partidos, ou bandeiras específicas. E, se os partidos tiverem meios para induzir a cooperação de seus membros através de sanções ou ameaça de sanções, os parlamentares ficarão limitados na execução de seu papel de representantes. Cabeperguntar, portanto, quemecanismosirão garantir autonomiaao representantepara decidir conforme seu entendimento do que é o mel hor para a nação. E o que garante que as decisõesserão tomadas após deliberação, jáqueexistea possibilidadedemudança deposição?

\section{REPRESENTAÇÃO POLÍTICA, PARTIDOS POLÍTICOS E REPRESENTATIVIDADE}

O debateem torno da autonomia do representante, na teoria da representação, faz referência, em geral, à rel ação entre representanteerepresentado, sem incluir os partidos políticos nessa relação. Para seentender as implicações da migração partidária para a representação política, seria necessário compreender as relações quese estabelecem entre representantee representado, eentre o representante e seu partido. Nesta seção, farei menção extensiva aos teóricos quetratam do tema da representação política, para apreender a compl exidade do tema e a controvérsia que el e gera, para que, assim, possamos compreender quenão há nada deóbvio na relação entremigração partidária erepresentação política.

Para Pitkin (2006), o debate podeser sintetizado da seguinteforma: "um representante deve fazer o queseus eleitores querem ou o queeleacha que é melhor?" (p.30). E completa: "A discussão nasce do paradoxo inerenteao próprio significado da representação: tornar presente dealguma forma o que apesar disso não está literal mente presente" (grifo da autora, 2006).

A autora acrescenta queessedebateteórico traz consigo questões da maior importância epreocupações bastantesubstantivas, entre las aquestão do papel dos partidos políticos na relação entrerepresentanteserepresentados (2006).

A noção derepresentação surge deumafigura do direito privado, em que o representantetem obrigação legal em relação ao representado. A representação política surge deumamatriz privatista, na Idade Média, quando os representantes não eram mais do que mandatários, e, nesse sentido, estavam ligados aos seus mandantes por instruções específicas (Gurza Lavalleetal, 2006; Manin, 1997; Pitkin, 2006; Sartori, 1962; Urbinati, 2006).

Do mandato imperativo, instruído, para a concepção derepresentação política moderna, com autonomia do representanteem rel ação ao representado, conformea concebemos hoje, permanece o nome, paraindicar, segundo Sartori, a intenção ou o fim, queé: "garantir que (os representantes) [...] secomportem da maneira como um mandatá rio deveria comportar-secom relação ao mandante, cuidando, não deseus própriosinteresses, mas dosalhei os" (Sartori, 1962, p.15).

A independência do representanteem relação ao representado surgejuntamentecomaconcepção dequeesterepresentaedevedecidir pelanação. ParaSartori, aassociação da palavranação àidéia de representação traz conseqüências quantoà concepção darepresentação emsi, quepassaadesignar não maisumarelação entreo'deputado eseu mandante', mas um poder concedido ao representante, a saber: o poder de decidir, conforme seu entendimento, o queémel hor paraanação como um todo. 
ParaUrbinati (2006), enquanto a sociedade for legal menteigual, mas social mente desigual, o paradigmado free-mandate não éuma ameaça para representação ou para a representatividade. Paraa autora, equality as legal status means that the representatives must represent theentirenation and that their will is not bound to instructions by their electors (p.44).

Por outro lado, a autora afirma que: since citizens are socially not equal [...] and seek equality through political action and the law, representatives cannot ignore their voices and claims (2006). Para ela, enquanto aigual dadelegal determinariaqueos representantes representamanação, transcendendo seuseleitores, aigual dademoral, ou aluta por igualdadeeconômica esocial, por outro lado, demanda queos representantesacedamaseus eleitores.

Sartori, ao contrário deUrbinati, acreditaque, quando o representanteganhaautonomia demasiada, arelação derepresentação passa aser ameaçada, pois a independência excessiva do representante em relação ao eleitor põe em questão a representatividadedos representantes edosistema como um todo. Gurza Laval leetal (2006) explicitam essa afirmação, dizendo quea representação:

... leva no seu cerne uma duali dade constitutiva graças à qual a mera existência da representação, mesmo que legal menteinstituída ou respaldada por mecanismo obrigatório de autorização, não garante a representativi dade ou correspondência com a vontade ou interesse dos representados. (2006).

Manin (1997) destaca quea esfera deatividades dos governos representativos modernos é detal forma complexa, quetornaa prática do mandato imperativo impossível. O autor nos lembra ainda que os representantes, uma vez el eitos, têm, nas el eições subseqüentes, o incentivo para manter suas promessas, pois os eleitores podem ou não reel egêlos.

A questão da representatividade, colocada dessa forma, nada tem a ver com a distribuição de cadeiras entreos partidos no parlamento, mas sim com a correspondência entre o interesse dos re presentados eas decisões tomadas pel os represen- tantes. Ou seja, passa pela identificação dos eleitores com aquel es queos representam, mas, principalmente, está relacionada à forma como as demandas dos eleitores chegam esão atendidas por aqueles queos representam.

Mas ondeo partido político seencaixanessa discussão? Partidos políticos são inseparáveis das democracias representativas. Schattschnei der afirma quepolitical parties created democracy, and [...] democracy is unthinkable save in terms of parties (1942, apud Aldrich, 1995, p.3). Os partidos organizam o processo el eitoral escol hendo os candidatos e simplificando a informação para o eleitor, que podeanal isar seu candidato a partir da plataforma partidária. Organizamainda o processo deci sório, agregando interesses epossi bilitando maior previsibilidade nas decisões (Aldrich, 1995, p.3; Cox; Mccubbins, 1993).

No entanto, Manin, emsua descrição sobre a evolução dos governos representativos, aponta para o fato de que, embora os partidos políticos sejam concebidos como um el emento constitutivo do governo representativo, os founding fathers entendiam a divisão do parlamento em partes ou em facções como al go negativo, que poria em xeque o sistema representativo.

A legitimação dos parti dos políticos como o canal entre representantes e representados foi precedi da por um debate que percebia a ascensão dos mesmos como um indicativo do fim do governo representativo. Entre as principais preocupações dos autores, aparece a questão da manutenção daautonomia do representante, necessária para que ele mesmo representasse a nação como um todo, ea questão da discussão préviaà tomada de decisões, destacada desde a origem mais remota como a função primordial dos parlamentos. E, passada a sensação de crise, surgiu a i déia de que os partidos aumentavam a comunicação entre a sociedadeeos governos, aumentando a identificação entreel eitores eseus representantes, o quetornaria a representação mais democrática (Manin, 1997)

Essa é a posição defendida por Urbinati (2006), ao afirmar quesó através dos partidos po- 
líticos épossível assegurar representatividade. A autora argumenta que as el eições determinam as responsabilidades eos limites deumgoverno, mas não sua representatividade. Afirma ai nda que, somente através dos partidos políticos, é possível garantir que os representantes sejam partidários de idéias e de ideologias e não de seus próprios interesses.

Sartori (1962), no entanto, afirma quea inserção do partido político compl exifica a relação entrerepresentanteserepresentados. Nas palavras do autor,

deve-se considerar que, na relação entre el eitores-eleitos, se inserem - e com vastos reflexos os partidos políticos. E a intervenção dos partidos modernos de organização complica o quadro, inserindo nel e pertencimentos adquiridose múltiplos (p.124).

O autor afirma ainda que a introdução da pal avra nação, associada à idéia derepresentação, conquanto privada desentido jurídico, éo quedá sentido à própria representação eo que garanteo

único sustentáculo que permite ao deputado não obstante todos os víncul os substanciais de submissão que se criam entre o eleitorado e o eleito, eainda, entre o eleito e o partido pelo qual sefaz eleger - legitimar ereivindicar um direito à sua autonomia de opinião e de vontade (1962, p.75, grifo acrescido).

MesmoUrbinati (2006), queentendeserem os partidos políticosfundamentais para garantir a representatividade da democracia - para garantir quea representação não setorneapenas o atendimento de uma clientela-, ao sereferir à independência do representanteem relação ao el eitorado, afirma que: representatives [...] are asked to rely only upon their reason to judge according to general interest (p.44).

Sartori (1962) completa ainda, afirmando que, ao privar o representanteda autonomia, seja em relação ao el eitor, seja em relação ao partido, transforma-seo parlamento em uma casa sem ra zão de ser. Para o autor:

... se, porém, as assembléias são ou se tornam personificadas por representantes que vivem por meio da política - homens de partido cujo futuro estáligado à confirmação no posto - o parlamento correo risco deperder toda asua independência efetiva, e detransformar-se numa espécie de caixa de ressonância de um sistema mais que parlamentar, partitocrático (p.131).

Schimitt (1988) revela a mesma preocupação. Para o autor, o Parlamento deve ser fundado sobre o princípio "of discussion and openness", quefica ameaçado quando o parlamentar não possui independência em relação ao el eitor eao partido queo el egeu.

A preocupação desses autores éque o partido domine o processo de decisão de tal forma, quea autonomi a do representante fiquecomprometida. Garantir ao parlamentar o direito de discutir edecidir sobrequal quer propostaégarantira representatividadeda nação queo escol heu como seu representante. Garantir a autonomia do representanteégarantir queo processo de deli iberação aconteça, e que o parlamentar possa tomar decisões após esse processo, conformeo seu entendimento do queémel hor para nação.

Manin aponta, entre os princípios institucionais dos governos representativos, o princípio da "trial by discussion", definido pelo o autor como um tipo de comunicação em que uma parteécapaz demudar a opinião da outra através deargumentos impessoais erelacionados ao futuro. Dado queo parlamentoéum corpo del iberativo, o queseespera dos parlamentares équeeles deliberem para chegar a conclusões, e esse éum dos motivos pel os quais os parlamentares não podem ser limitados pel os desejos de seus el eitores.

No entanto, na democracia de partidos, a autonomia dos parlamentaresécomprometidanão pelos el eitores, mas pel os partidos, pois a decisão dos partidos sobre cada questão étomadaantes da entrada no plenário. $\mathrm{E}$, uma vez que os partidos políticostenhammeios para coagir seus membros a seguiremas diretrizes partidárias, o parlamentar não tem autonomia para mudar de opinião como correr dos debates, o que põeem xequea autonomia do representanteeleito.

Para Manin, o surgimento da democracia de partidos implica também o deslocamento da 
arena onde ocorrem as discussões, que deixam o plenário e passam a ocorrer no interior dos partidoseentreoslideres partidários. Deve-seressaltar que, nessecaso, a visibilidadedas decisõesécomprometida, pois elas passam a ser tomadas em gabinetesfechados.

\section{CONSIDERAÇÕES FINAIS: sintetizando os principais argumentos}

A conclusão dosanalistas da migração partidáriano Brasil - dequeos parlamentares, aotrocarem de partido, promovem uma crise de representatividade do parlamento - é apressada, poispoderíamos imaginar ser a migração partidária uma vál vula deescapepara aquelesquenão encontram espaço parasemanifestar dentro deseus partidos. ${ }^{4}$ Se pensarmos que o eleitor é quem define que parlamentares irão assumir as cadeiras determinadas parao partido, devemosimaginar queesse eleitor apóieas idéias dessecandidato específico.

As pesquisas de Freitas, Limongi e Melo (2004) demonstram queos parlamentares buscam partidos muito próximos no espectro ideológico, o queimplica não trazer a migração partidáriauma mudançaradical no comportamento do parlamentar. Nesse sentido, poderíamos supor que as trocas delegenda não afetariama rel ação entreo eleitor eseu representante.

Por fim, quando se debatefidelidade partidária a partir de uma visão puramente institucional ista, acaba-sepor esquecer queos parlamentares têm uma função importanteno parlamento, queéa de governar em nome da nação, o que supõe al guma autonomia em relação ao seu partido, ou a possibilidade de discutir, dentro do partido, qual a posição queserátomada.

(Recebido para publicação em janeiro de 2008) (Aceito em março de 2008)

${ }^{4}$ No Brasil, os al tos índices de disciplina partidária refletem o fato de que os partidos políticos têm meios para induzir seus membros à cooperação, o que revel a que os parlamentares têm pouca autonomia para agir contra o partido (Figueiredo; Limongi, 1999).

\section{REFERÊNCIAS}

ALDRICH, John $\mathrm{H}$. Why parties? Chicago: University of Chicago Press, 1995.

ARAÚJO, Marcelo. Mudança partidária. A evolução das migrações partidárias na Câmara dos Deputados: 1979/ 1999. 2000. Dissertação (Mestrado) - Universidade de São Paulo. São Paulo: 2000,

BURKE, Edmund. The writings and speeches of Edmund Burke. Oxford: University Press, Oxford, 1981. v.2.

COX, Gary; MCCUBBINS, Matthew. Legislative leviathan: party government in the House. California: University of California Press, 1993.

DESPOSATO, Scott. Parties for rent? Ambition, ideology, and party-switching in Brazil's chamber of deputies. American Journal of Political Science, [S.I.], v.50, n.1, 2006.

DINIZ, Simone. As migrações partidárias e o cal endário el eitoral. Revista de Sociologia e Política, Curitiba, 2000.

DOWNS, Anthony. Uma teoria econômica da democracia. São Paulo: EDUSP, 1999.

FIGUEIREDO, Argelina Cheibub; LIMONGI, Fernando. Executivo e Legislativo na Nova Ordem Constitucional. Rio de Janei ro: Fundação Getúlio Vargas Editora, 1999.

FREITAS, Andréa. Migração partidária na Câmara dos Deputados. [S.I.], 2008. (mimeo.)

GURZA LAVALLE, Adrián; HOUTZAGER, Meter CASTELLO, Graziela. Democracia, Plural ização da Repre sentação e Sociedade Civil. Lua N ova, São Paulo, CEDEC, n.67, 2006

LIMA JUNIOR, Olavo Brasil. Democracia e instituicões políticas no Brasil dos anos 80. São Paulo: Loyola, 1993.

LIMONGI, Fernando; FREITAS, Andréa. Migração partidária e comportamento parlamentar. [S.I.], 2005. (mimeo)

MANIN, Bernard. 1997. The pinciples of representative governament. In: ; PRZEWORSKI, Adam; STOKES, Susan (Org.) Democracy, accountability and representation. Cambrige. University Press, 1999.

MARENCO, André. Migração partidária. In: AVRITZER, Leonardo; ANASTASIA, Fátima (Org.) Reforma política no Brasil. São Paulo: Editora UFMG, 2006.

MELO, Carlos Ranulfo. Retirando as cadeiras do lugar, migração partidária na Câmara dos Deputados (19852002). Belo Horizonte: Editora UFMG, 2004.

MERSHON, Carol; HELLER, William. Legislator preferences, party desires: party switching and the foundations of policy making in legislatures. Paper proposto para MEETINGS OF THE INTERNATIONAL STUDIES ASSOCIATION. [S.I.]: 2005.

PITIKIN, F. Hanna. Representação, palavras instituições e idéias. Lua Nova, São Paulo, CEDEC, n.67, 2006.

SARTORI, Giovanni. A teoria da representação no estado representativo moderno. Revista Brasileira de Estudos Políticos. Belo Horizonte, 1962.

\section{UNB, 1983}

Partidos e sistemas partidários. Brasília: Zahar/

SCHMITT, Carl. The crisis of parliamentary democracy. Cambridge: MIT Press. 1988.

URBINATI, Nadia. Representative democracy. University of Chicago Press, 2006

O que torna a representação democrática? Lua Nova, São Paulo, CEDEC, n.67, 2006a.

ZULINI, Jaqueline. Migracão partidária na Câmara dos Deputados (1946-1964). [S.I.], 2008. (mimeo). 
INFIDELIDADE PARTIDÁRIA E REPRESENTAÇÃO POLÍTICA: alguns argumentos sobre a migração partidária no Brasil

\section{Andréa Freitas}

Este texto problematiza o tema da migração partidária de parlamentares e suas conseqüências sobre a representação política, explorando, especialmente, a relação entre o representante e seu partido. A idéia é trazer alguns argumentos iniciais sobre as conseqüências das trocas de legenda por políticos exercendo o mandato, que ultrapasse a perspectiva analítica dos procedimentos ou das regras de conversão de votos em tema e a controvérsia que ele gera.

PALAVRAS-CHAVE: partidos políticos, migração partidária, representação política, mandato.
PARTY INFIDELITY AND POLITICAL REPRESENTATION: some arguments about the partidary migration in Brazil

\section{Andréa Freitas}

This text problematizes the theme of the partidary migration of members on political representation, exploring, especially, the relationship between the representative and his party. We strive to bring some initial arguments, on the consequences of the party changes for politicians exercising their term, that surpass the analytical perspective of
procedures or of the rules of conversion of votes in chairs, revealing the complexity of the theme and the controversy it generates.

Keywords: political parties, partidary migration, political representation, term.
INFIDÉLITÉ AU PARTIET

REPRESENTATION POLITIQUE: quelques arguments concernant la migration d'un parti à l'autre au Brésil

\section{Andréa Freitas}

Cet article pose le problème du thème de la migration des parlementaires d'un parti à l'autre et de ses conséquences sur la représentation politique. On y analyse tout spécialement la relation entre les représentants des partis et leur parti. L'intention est d'apporter quelques arguments au départ sur les conséquences dues au fait que des élus politiques changent de parti au cours de leur mandat. On va au-delà d'une perspective analytique de procédé ou de règle de conversion des votes en sièges, montrant la complexité du thème et la controverse qui en découle.

MOTS-CLÉs: partis politiques, changement de parti, représentation politique, mandat. 